\title{
Amniotic Fluid Changes and Doppler Studies in Unexplained Oligohydramnios before and after Intravenous Maternal Hydration
}

\author{
Abd El Moneim M. Zakaria ${ }^{1}$, Abd El Monsef A. Sedek ${ }^{2}$, Nader A.Abohassan ${ }^{\text {* }}$ \\ ${ }^{1}$ Department of Obstetrics and Gynecology,Faculty of Medicine Al-Azhar University \\ ${ }^{2}$ Department of Obstetrics and Gynecology, Elmenshawy General Hospital \\ *Corresponding author:Nader A.Abohassan; Mobile: 01061010323; Email:dr_rare2010@yahoo.com
}

\begin{abstract}
Background: role of intravenous hydration is well documented for the treatment of oligohydramnios. The present study concentrated on the efficacy of intravenous hydration in cases of unexplained oligohydramnios.Aim of the study: this study aimed to evaluate the effect of intravenous maternal hydration (hypotonic and isotonic fluid) in pregnancies with third-trimester oligohydramnios on amniotic fluid index and uteroplacental perfusion and fetal blood flow. Patients and Methods: this study was conducted in the Department of Obstetrics and Gynecology, Faculty of Medicine, Al-Azhar University, Egypt, during the period from January 2017 to January 2018. A total of 60 pregnant women were included and parameters like age, parity, BMI, amniotic fluid index, urine specific gravity, hematocrit value, umbilical artery pulsatility index and uterine artery pulsatility index before and after maternal hydration were noted and compared. Results: intravenous maternal infusion of $(1 / 2)$ normal saline $(0.45 \%)$ at a rate of $1000 \mathrm{ml} / \mathrm{hr}$ for two hours has statistically difference in the mean amniotic fluid index , in mean urine specific gravity, in mean umbilical artery pulsatility index and in mean uterine artery pulsatility index immediately after hydration, $72 \mathrm{hr}$ and one week after hydration $(p<0.05)$. Conclusions: maternal intravenous hydration with hypotonic fluid can be used in the treatment of oligohydramnios
\end{abstract}

Key words: amniotic fluid index, maternal hydration, oligohydramnios.

\section{Introduction}

Amniotic fluid is important for the maintenance of fetal well-being ${ }^{(1)}$. It provides a supportive environment for fetal development. It protects the fetus from trauma and infection through its dampening and bacteriostatic properties. It allows for fetal movement and thus fosters the development of the fetal musculoskeletal system. It prevents compression of the umbilical cord and placenta and thus protects the fetus from vascular and nutritional compromise (2). Amniotic fluid deficiency, i.e., oligohydramnios is defined as amniotic fluid index (AFI) $5.0 \mathrm{~cm}$ or less (3). Oligohydramnios can have multiple impacts on the prognosis of the pregnancy ${ }^{(1)}$.Amniotic fluid is important for the development of fetal organs, especially the lungs. Too little fluid for long periods may cause abnormal or incomplete development of the lungs called pulmonary hypoplasia. At delivery, oligohydramnios may increase the risk for compression of the umbilical cord and aspiration of thick meconium (4). Oligohydramnios may be the result of fetal renal tract abnormality or damage, placental insufficiency, including impaired maternal- placental blood flow and isolated placental chromosomal mosaicism, associated with impaired fetal growth, drugs such as prostaglandin synthetase inhibitors, acute or chronic amniotic fluid leakage ${ }^{(5)}$.In some cases, there are no evident fetal or maternal causes, and the condition is called isolated or unexplained oligohydramnios ${ }^{(1)}$.Amniotic fluid volume represents a dynamic state that is influenced by both fetal and maternal conditions ${ }^{(6)}$.Adequate amniotic fluid volume is maintained by a balance of fetal fluid production (lung liquid and urine) and resorption (swallowing and intramembranous flow). Even though different hypotheses have been advanced on the mechanisms regulating this turnover, the inflow and outflow mechanism that keeps amniotic fluid volume within the normal range is not entirely clear ${ }^{(7)}$. An additional route of amniotic fluid absorption is required to balance fluid output and absorption; this absorption is theorized to occur across the fetal amnion into the fetal vasculature, and has been named the intramembranous (IM) pathway. In addition, amniotic fluid volume depends on fetal hydration. All water in the conception ultimately derives from the mother; therefore 
placental water flux is also a factor in determining amniotic fluid volume ${ }^{(8)}$.The determination of an association between oligohydramnios and poor fetal outcome requires the investigation of the factors involved in the maintenance of $\mathrm{AF}$ volume, and maternal hydration among these seems to play a relevant role ${ }^{(9)}$.Several treatments have been tried to maintain amniotic fluid volume and thus promote lung development in pregnancies complicated by oligohydramnios ${ }^{(10)}$.An alternative, noninvasive option to increase amniotic fluid volume is maternal hydration. Maternal hydration therapy has been used by Umber ${ }^{(\mathbf{1 1})}$ to restore amniotic fluid volume to its normal range and thereby to reduce the associated perinatal morbidity and mortality. A study had addressed the relationship between maternal intravascular volume and amniotic fluid volume. Maternal hydration has been the focus of studies in women with oligohydramnios ${ }^{(9)}$. Drinking too much water may not be pleasant for some people, so intravenous fluid loading is an alternative route of maternal hydration (9). Doppler flowmetry of the umbilical artery in oligohydramnios showed a higher sensitivity, specificity and accuracy to diagnose perinatal death than the measurement of oligohydramnios and the Apgar score ${ }^{(\mathbf{1 2})}$. The mechanism by which maternal hydration increases the amniotic fluid volume, in women with oligohydramnios, involves improvement in uteroplacental perfusion detected by Doppler studies ${ }^{\left({ }^{(13)}\right.}$. This study aimed to evaluate the effect of intravenous maternal hydration (hypotonic and isotonic fluid) in pregnancies with third-trimester oligohydramnios on amniotic fluid index and uteroplacental perfusion and fetal blood flow.

\section{Patients and methods}

The present study was carried out in the Department of Obstetrics and Gynecology, Faculty of Medicine, AlAzharUniversity, Egypt, during the period from January 2017 to January 2018. This study was carried out on sixty pregnant patients with third trimester (32-37 weeks) unexplained oligohydramnios. Patients were chosen from the obstetrical out patients and hospital cases, after complete history taking and complete general and obstetrical examination, to include cases with unexplained oligohydramnios only.

\section{INCLUSION CRITERIA :}

Third-trimester, singleton pregnancy.

Well-established gestational age (by date and $\mathrm{U} / \mathrm{S}$ ).

Diagnosed oligohydramnios using amniotic fluid index $\leq 5 \mathrm{~cm}$.

Intact membranes.

EXCLUSION CRITERIA:

Multiple pregnancies

Dead fetus

Premature rupture of membranes

(History, Abdominal examination,

Sterille Cusco speculum examination).

Maternal medical diseases (Severe anemia, cardiac disease, renal disease, moderate or severe preeclampsia, hypertension, or diabetes).

Fetal structural malformations.

\section{METHODS:}

Patients were instructed to drink 3 liters of water, divided on the day, for three days before the study and during the study period.

Written consent was obtained from the patients who were included in the study, after explaining to them their condition and possible fetal complications and possible beneficial effect of maternal hydration. The study was approved by the Ethics Board of Al-Azhar University.

\section{Conventional transabdominal ultrasound assessment was done.}

\section{Technique of ultrasound examination:}

The ultrasound machine used was VOLUSON E6 , with a curvilinear abdominal probe, 3.5 Hertz.

Trans-abdominal ultrasound was performed to all patients while the patient was in a slightly tilted position with the head of the bed raised 30 degrees and with a small pillow under the right loin.

Examination was performed for:

- Diagnosis of oligohydramnios (amniotic fluid index $\leq 5 \mathrm{~cm}$ ).

- Detection of fetal viability.

- Estimation of gestational age.

- Exclusion of multiple pregnancies.

- Exclusion of fetal structural anomalies. 
Studied patients with oligohydramnios, who met the inclusion criteria, were randomized to 2 groups (by using odd and even numbers):

Group I (Odd numbers): included 30 patients Destined to intravenous infusion of normal saline $(0.9 \%)$ at a rate of $1000 \mathrm{ml} / \mathrm{hr}$ for two hours.

Group II (Even numbers): included 30 patients

Destined to intravenous infusion of $(1 / 2)$ normal saline $(0.45 \%)$, at a rate of $1000 \mathrm{ml} / \mathrm{hr}$ for two hours.

Maternal vital signs were monitored every 15 minutes during i.v. hydration to avoid overload side effects

Patients in each group were assessed before, at the end of the 2-hours hydration period, 72 hours after hydration and after one week after hydration by:

Amniotic fluid index measurement.

Doppler study of the uterine and umbilical arteries.

Hematocrit value

Urine analysis for specific gravity

\section{TECHNIQUE of ULTRASOUND:}

\section{I - Amniotic fluid index}

The uterus was divided into four quadrants by using the umbilicus as one reference point dividing the uterus into upper and lower halves, and the lineanigra was then used to divide the uterus into right and left halves.

A convex transducer was then placed on the maternal abdomen along the longitudinal axis of the mother, with the transducer head being perpendicular to the floor in each of the four uterine quadrants.

The vertical diameter of the largest amniotic fluid pocket, in each uterine quadrant once identified, was measured. The measurements obtained from each uterine quadrant were summed up to represent the amniotic fluid index.

Amniotic fluid index $\leq 5 \mathrm{~cm}$ was labeled as low amniotic fluid volume, while amniotic fluid index $\geq 5.1$ to $20 \mathrm{~cm}$ was labeled as normal amniotic fluid volume and amniotic fluid index $\geq 20 \mathrm{~cm}$ was labeled as high amniotic fluid volume.

We were careful to maintain a perpendicular relationship of ultrasound transducer to the floor to avoid falsely enlarged amniotic fluid pocket ${ }^{\left({ }^{(3)}\right.}$.We extended the ultrasound evaluation to the lateral margins of the uterus to guard against erroneous inadequate amniotic fluid volume impression, as adequate amniotic fluid may be located in the flanks of the supine patient.

For each amniotic fluid index, the mean of two measurements was used for analysis.

\section{Doppler study}

The angle between the ultrasonographic beam and the direction of blood flow was always $<30$ degrees. The Doppler signals from the studied arteries were recorded with a $3.5 \mathrm{MHz}$ curved array duplex transducer. Doppler indices were calculated by the dedicated software supplied within the Doppler equipment. The average value of at least three consecutive waveforms was calculated.

\section{Umbilical artery Doppler:}

The uterine contents were scanned to select an area of amniotic cavity with several loops of the umbilical cord. Ideally, these cord loops should not be close to the cord insertion. Then, using a pulsed-wave-Doppler on a free loop of the cord, and the characteristic sound and shape of the umbilical artery was identified.

When the screen showed several waveforms of similar height, the image was frozen. The umbilical artery Doppler indices from at least 3 consecutive waveforms was obtained and averaged to determine pulsatility index (PI) where [PI = (maximal systolic velocity - least diastolic velocity) / average].

A minimum of 3 separate readings were averaged before the final values were obtained. Because of the potential effect of the fetal breathing movements on waveform variability, recordings were performed during periods of fetal apnea ${ }^{(\mathbf{1 4})}$.

\section{Uterine artery Doppler}

Uterine artery was examined by directing the probe to the parauterine area in the region of the lower uterine segment ${ }^{(15)}$.Pulsatility index was calculated by the dedicated software supplied within the Doppler equipment.

\section{HEMATOCRIT VALUE:}

Baseline maternal blood sample was taken immediately before the hydration for direct measurement of hematocrit which was performed by standard laboratory techniques. At the end of the 2-hour hydration period, 72 hours 
after hydration, and one week after hydration, blood samples was taken and analyzed as before.

\section{URINE ANALYSIS FOR SPECIFIC GRAVITY:}

Baseline maternal urine sample was taken immediately before the hydration for direct measurement of specific gravity, which was performed by standard laboratory techniques. At the end of the 2-hour hydration period, the patient was instructed to micturate again and then the next sample was collected for analysis. Urine samples were taken also 72 hours and one week after hydration for analysis.

Both the patients and the examiner were blinded to the study groups.

\section{STATISTICAL ANALYSIS:}

The clinical data were recorded on a report form. These data were tabulated and analyzed using the computer program SPSS (Statistical package for social science) version 16 to obtain:

Descriptive data

Descriptive statistics were calculated for the data in the form of:
Mean and standard deviation (Mean+SD) for quantitative data.

Frequency and distribution for qualitative data.

\section{Analytical statistics}

In the statistical comparison between the different groups, the significance of difference was tested using one of the following tests:

Student's t-test: used to compare means of two groups of quantitative data.

2. Paired t test: used to compare means of two variables of the same group.

Inter-group comparison of categorical data was performed by using Fisher's exact test (FET).

A $P$ value $<0.05$ was considered statistically significant (S) while $>0.05$ statistically insignificant $\mathrm{P}$ value $<0.01$ was considered highly significant (HS) in all analyses.

\section{Results}

The present study was carried out in the Department of Obstetrics and Gynecology, Faculty of Medicine, Al-Azhar University, Egypt, during the period from January 2017 to January 2018. A total of 60 pregnant women were recruited in the study. Table- 1 shows characteristics of included women

Table 1: characteristics of included women

\begin{tabular}{|c|c|c|c|c|c|c|}
\hline \multirow[t]{2}{*}{ Variable } & \multicolumn{2}{|c|}{ Group I $(n=27)$} & \multicolumn{2}{|c|}{ Group II $(n=27)$} & \multirow{2}{*}{$\begin{array}{l}\text { Student } \\
\text { t Test }\end{array}$} & \multirow[t]{2}{*}{$\mathrm{P}$ value } \\
\hline & Mean \pm SD & Range & Mean \pm SD & Range & & \\
\hline Age & $27.86 \pm 5.74$ & $19-35$ & $29.77 \pm 4.21$ & $22-35$ & 1.26 & $0.215 \mathrm{NS}$ \\
\hline $\mathrm{Wt}(\mathrm{Kg}) *$ & $72.91 \pm 9.13$ & $59-87$ & $73.5 \pm 8.44$ & $60-85$ & 0.223 & $0.825 \mathrm{NS}$ \\
\hline GA(wk )* & $33.55 \pm 2.82$ & $29-37$ & $33.41 \pm 2.32$ & $30-37$ & 0.175 & 0.862 NS \\
\hline Gravidity & $2.36 \pm 1.33$ & $1-5$ & $2.77 \pm 1.07$ & $1-4$ & 1.13 & $0.266 \quad \mathrm{NS}$ \\
\hline Parity & $1.09 \pm 1.02$ & $0-3$ & $1.14 \pm 0.64$ & $0-2$ & 0.177 & 0.86 \\
\hline
\end{tabular}

This table shows that there was no statistically significant difference regarding mean age, weight in kilograms, gestational age (weeks), gravidity and parity between groups I and II (p>0.05) i.e. both groups matched. 
Amniotic Fluid Changes and Doppler....

Table 2: comparison between groups I and II regarding amniotic fluid index (AFI)

\begin{tabular}{|c|c|c|c|c|c|c|}
\hline \multirow[t]{2}{*}{ Variable } & \multicolumn{2}{|c|}{ Group I ( $n=27)$} & \multicolumn{2}{|c|}{ Group II (n=27) } & \multirow{2}{*}{$\begin{array}{l}\text { Student } \\
\text { t test }\end{array}$} & \multirow[t]{2}{*}{$P$ value } \\
\hline & Mean \pm SD & Range & Mean \pm SD & Range & & \\
\hline $\begin{array}{ll}\text { AFI } & \text { before } \\
\text { hydration } & \end{array}$ & $3.86 \pm 0.99$ & $2-5$ & $3.73 \pm 1.03$ & $2-5$ & 0.447 & $\begin{array}{l}0.657 \\
\text { NS }\end{array}$ \\
\hline $\begin{array}{l}\text { AFI(immediately) } \\
\text { after hydration }\end{array}$ & $4.73 \pm 1.28$ & $2-6$ & $6.73 \pm 1.24$ & $5-9$ & 5.26 & $\begin{array}{l}0.001 \\
S\end{array}$ \\
\hline $\begin{array}{l}\text { AFI } 72 \text { hr after } \\
\text { hydration }\end{array}$ & $4.41 \pm 1.3$ & $2-6$ & $5.86 \pm 0.83$ & $5-7$ & 4.43 & $\begin{array}{l}0.001 \\
S\end{array}$ \\
\hline $\begin{array}{l}\text { AFI one week after } \\
\text { hydration }\end{array}$ & $4.41 \pm 1.3$ & $2-6$ & $5.41 \pm 0.73$ & $5-7$ & 3.15 & $\begin{array}{l}0.003 \\
S\end{array}$ \\
\hline
\end{tabular}

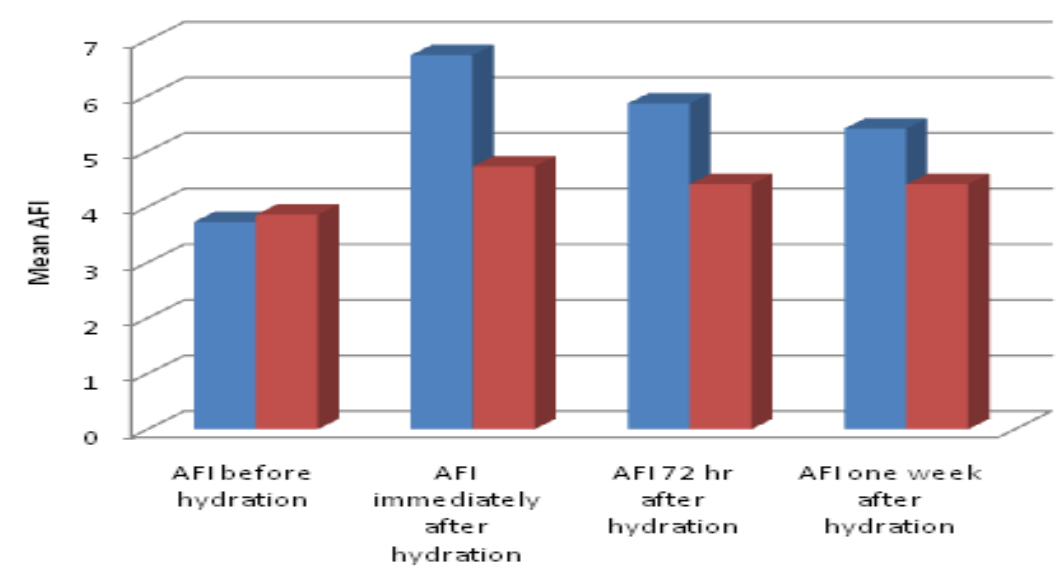

Group I

- Group II

Diagram 1: comparison between groups I and II regarding amniotic fluid index (AFI)

Table 3: comparison between groups I and II regarding urine specific gravity (USG)

\begin{tabular}{|c|c|c|c|c|c|c|}
\hline \multirow{2}{*}{ Variable } & \multicolumn{2}{|l|}{ Group I $(n=27)$} & \multicolumn{2}{|l|}{ Group II $(n=27)$} & \multirow{2}{*}{$\begin{array}{l}\text { Student } \\
\mathrm{t} \text { test }\end{array}$} & \multirow[t]{2}{*}{$P$ value } \\
\hline & Mean \pm SD & Range & Mean \pm SD & Range & & \\
\hline $\begin{array}{l}\text { USG before } \\
\text { hydration }\end{array}$ & $1017.0 \pm 2.45$ & $1014-1020$ & $1017.64 \pm 1.71$ & $1015-1020$ & 1.0 & $\begin{array}{l}0.323 \\
\text { NS }\end{array}$ \\
\hline $\begin{array}{l}\text { USG } \\
\text { immediately } \\
\text { after } \\
\text { hydration }\end{array}$ & $1012.9 \pm 1.11$ & $1012-1015$ & $1013.64 \pm 1.22$ & $1012-1020$ & 2.07 & $\begin{array}{l}0.044 \\
\text { S }\end{array}$ \\
\hline $\begin{array}{l}\text { USG } 72 \mathrm{hr} \\
\text { after } \\
\text { hydration }\end{array}$ & $1015.09 \pm 1.02$ & $\begin{array}{l}1015.09 \pm 1 \\
.02\end{array}$ & $1014-1017$ & $1015-1017$ & 3.504 & $\begin{array}{l}0.001 \\
S\end{array}$ \\
\hline $\begin{array}{l}\text { USG one } \\
\text { week after } \\
\text { hydration }\end{array}$ & $1016.09 \pm 1.48$ & 1014-1018 & $1016.5 \pm 1.44$ & $1015-1018$ & 0.93 & $\begin{array}{l}0.357 \\
\text { NS }\end{array}$ \\
\hline
\end{tabular}


This table shows that there was a statistically non-significant difference between groups I and II regarding urine specific gravity before hydration and one week after hydration. (p>0.05), but the difference was statistically significant immediately after hydration and 72 hr after hydration $(\mathrm{p}<0.05)$.

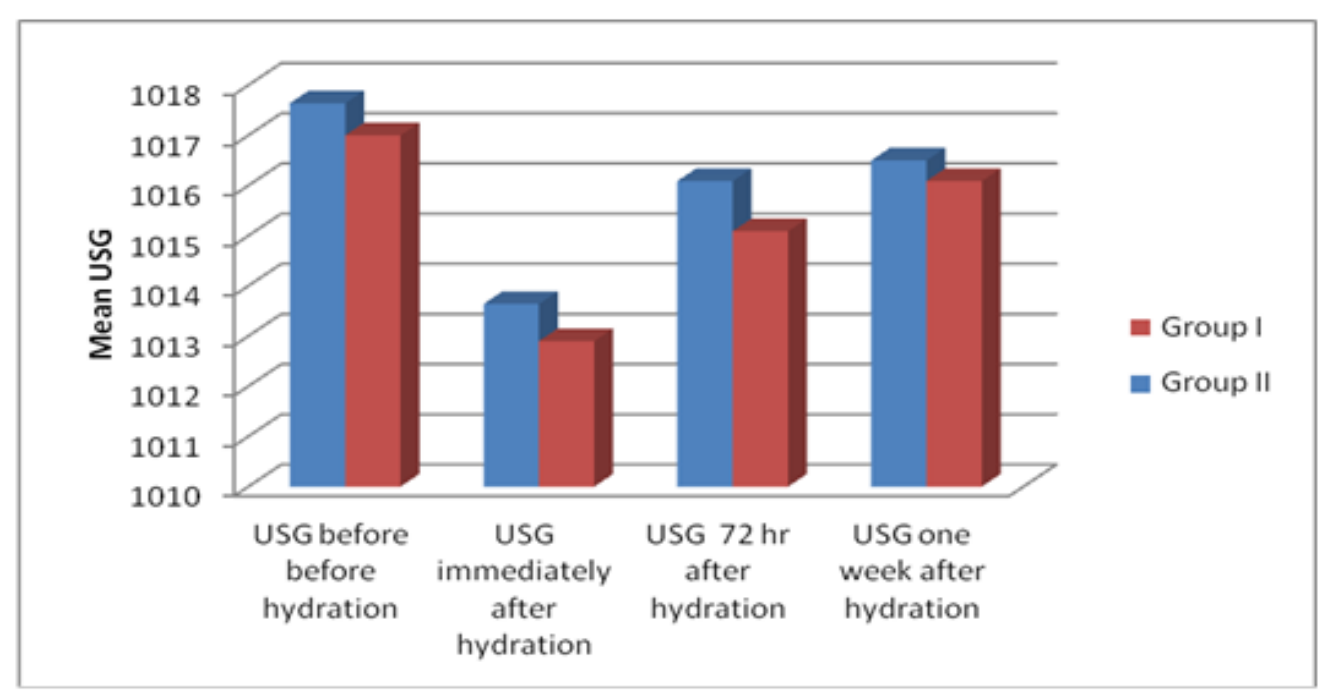

Diagram 2: comparison between groups I and II regarding urine specific gravity (USG)

Table 4: comparison between groups I and II regarding hematocrit (HCT)

\begin{tabular}{|c|c|c|c|c|c|c|}
\hline \multirow[t]{2}{*}{ Variable } & \multicolumn{2}{|c|}{ Group I $(n=27)$} & \multicolumn{2}{|c|}{ Group II (n=27) } & \multirow{2}{*}{$\begin{array}{ll}\text { Student } & \mathrm{t} \\
\text { test }\end{array}$} & \multirow[t]{2}{*}{ P value } \\
\hline & Mean \pm SD & Range & Mean \pm SD & Range & & \\
\hline $\begin{array}{l}\text { HCT before } \\
\text { hydration }\end{array}$ & $34.36 \pm 1.62$ & $32-37$ & $34.68 \pm 1.67$ & $32-37$ & 0.641 & $0.525 \mathrm{NS}$ \\
\hline $\begin{array}{l}\text { HCT } \\
\text { immediately } \\
\text { after } \\
\text { hydration }\end{array}$ & $32.18 \pm 1.97$ & $30-35$ & $33.36 \pm 1.71$ & $30-35$ & 2.13 & $\begin{array}{l}0.039 \\
S\end{array}$ \\
\hline $\begin{array}{l}\text { HCT } 72 \mathrm{hr} \\
\text { after } \\
\text { hydration }\end{array}$ & $33.64 \pm 1.62$ & $32-36$ & $34.36 \pm 1.71$ & $31-36$ & 1.45 & $0.154 \mathrm{NS}$ \\
\hline $\begin{array}{l}\text { HCT one } \\
\text { week after } \\
\text { hydration }\end{array}$ & $34.5 \pm 1.44$ & $33-37$ & $34.5 \pm 1.44$ & $32-36$ & 0 & $\begin{array}{l}1.0 \\
\text { NS }\end{array}$ \\
\hline
\end{tabular}

This table shows that there was a statistically non-significant difference between group I and group II regarding hematocrit value before hydration, $72 \mathrm{hr}$ and one week after hydration
( $p>0.05$ ), but the difference was statistically significant immediately after hydration $(\mathrm{p}<0.05)$. 
Amniotic Fluid Changes and Doppler....

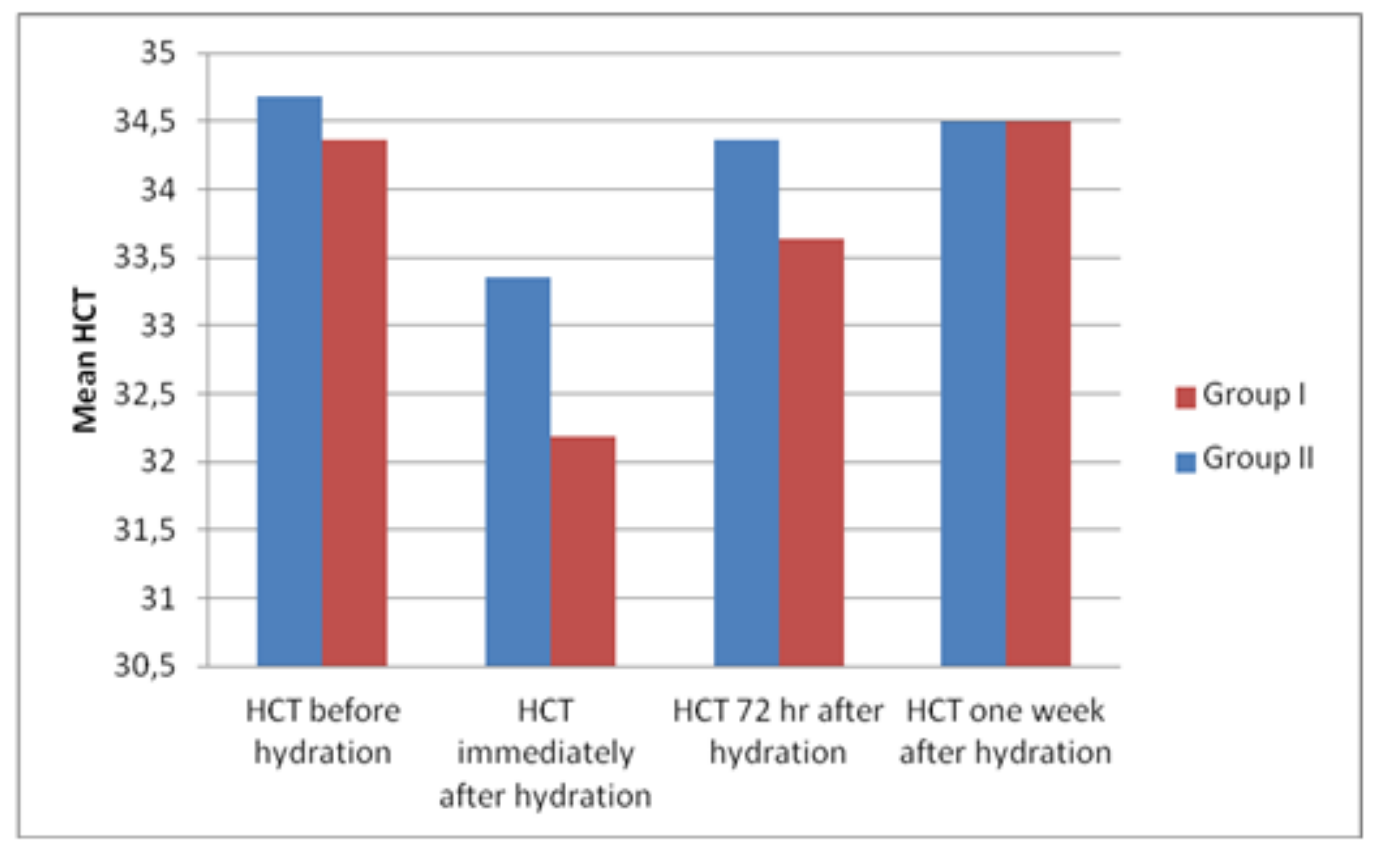

Diagram 3: comparison between groups I and II regarding hematocrit(HCT)

Table 5: comparison between groups I and II regarding umbilical artery pulsatility index (UmPI)

\begin{tabular}{|c|c|c|c|c|c|c|}
\hline \multirow[t]{2}{*}{ Variable } & \multicolumn{2}{|c|}{ Group I $(n=27)$} & \multicolumn{2}{|c|}{ Group II $(n=27)$} & \multirow{2}{*}{$\begin{array}{l}\text { Student } \\
\text { t test }\end{array}$} & \multirow[t]{2}{*}{$\overline{P \text { P value }}$} \\
\hline & Mean \pm SD & Range & Mean \pm SD & Range & & \\
\hline $\begin{array}{l}\text { UmPI before } \\
\text { hydration }\end{array}$ & $0.836 \pm 0.063$ & $0.69-0.92$ & $0.874 \pm 0.074$ & $0.76-0.89$ & 1.8 & $\begin{array}{l}0.079 \\
\text { NS }\end{array}$ \\
\hline $\begin{array}{l}\text { UmPI } \\
\text { immediately } \\
\text { after } \\
\text { hydration }\end{array}$ & $0.76 \pm 0.057$ & $0.69-0.83$ & $0.75 \pm 0.05$ & $0.67-0.81$ & 2.89 & $0.006 \mathrm{~S}$ \\
\hline $\begin{array}{l}\text { UmPI } 72 \mathrm{hr} \\
\text { after } \\
\text { hydration }\end{array}$ & $0.776 \pm 0.074$ & $0.66-0.81$ & $0.773 \pm 0.06$ & $0.68-0.85$ & 0.184 & $\begin{array}{l}0.855 \\
\text { NS }\end{array}$ \\
\hline $\begin{array}{l}\text { UmPI one } \\
\text { week after } \\
\text { hydration }\end{array}$ & $0.789 \pm 0.066$ & $0.72-0.89$ & $0.798 \pm 0.048$ & $0.72-0.86$ & 0.521 & $\begin{array}{l}0.605 \\
\text { NS }\end{array}$ \\
\hline
\end{tabular}

The table shows that there was a statistically non-significant difference between group I and group II before hydration, $72 \mathrm{hr}$ and one week after hydration ( $>0.05)$, but the difference was statistically significant immediately after hydration $(\mathrm{p}<0.05)$. 
Abd El Moneim Zakaria et al.

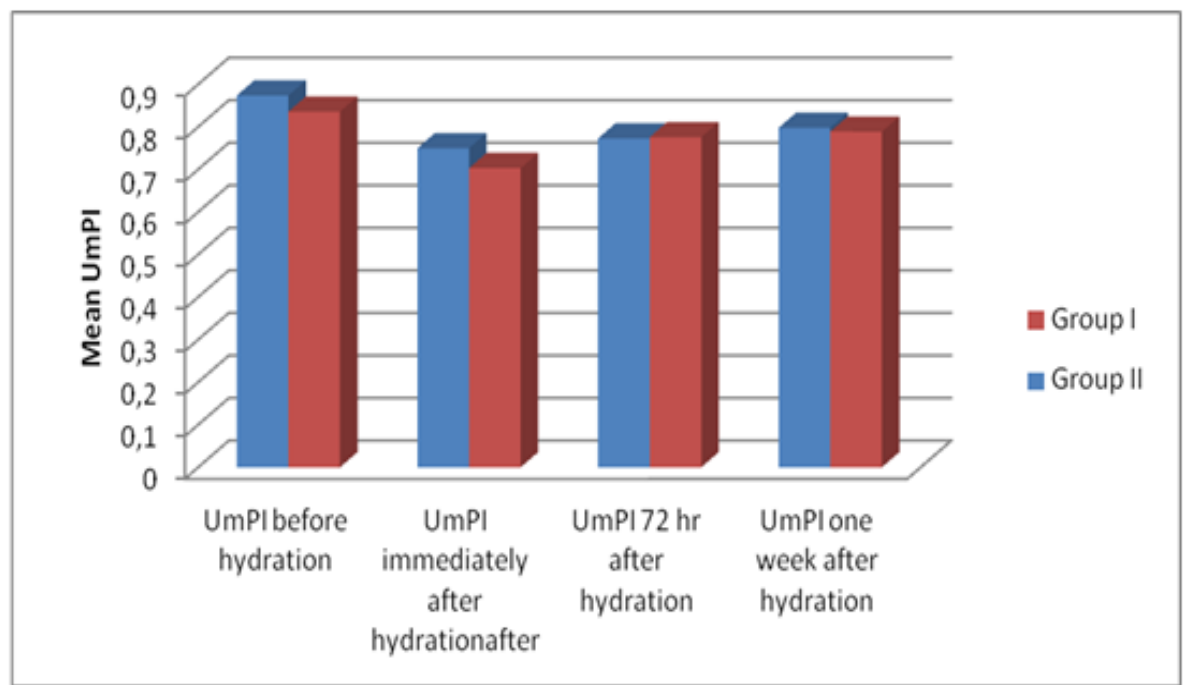

Diagram 4: comparison between groups I and II regarding umbilical artery pulsatility index (UmPI)

Table 6: comparison between group I and group II regarding uterine artery pulsatility index (UtPI)

\begin{tabular}{||l|l|l|l|l|l|l||}
\hline Variable & \multicolumn{2}{|l|}{ Group I (n=27) } & \multicolumn{2}{l|}{ Group II (n=27) } & $\begin{array}{l}\text { Student } \\
\text { t test }\end{array}$ & P value \\
\cline { 2 - 6 } & Mean \pm SD & Range & Mean \pm SD & Range & \\
\hline $\begin{array}{l}\text { UtPI before } \\
\text { hydration }\end{array}$ & $0.91 \pm 0.03$ & $0.87-0.96$ & $0.93 \pm 0.05$ & $0.84-0.98$ & 1.92 & $\begin{array}{l}0.062 \\
\text { NS }\end{array}$ \\
\hline $\begin{array}{l}\text { UtPI } \\
\text { immediately } \\
\text { after } \\
\text { hydration }\end{array}$ & $0.87 \pm 0.021$ & $0.85-0.91$ & $0.892 \pm 0.039$ & $0.82-0.93$ & 2.096 & $\begin{array}{l}0.042 \\
\text { S }\end{array}$ \\
\hline $\begin{array}{l}\text { UtPI 72 hr } \\
\text { after } \\
\text { hydration }\end{array}$ & $0.875 \pm 0.019$ & $0.85-0.89$ & $0.886 \pm 0.036$ & $0.81-0.92$ & 1.25 & $\begin{array}{l}0.22 \\
\text { NS }\end{array}$ \\
\hline $\begin{array}{l}\text { UtPI on } \\
\text { week after } \\
\text { hydration }\end{array}$ & $0.902 \pm 0.02$ & $0.87-0.92$ & $0.918 \pm 0.041$ & $0.83-0.96$ & 1.61 & $\begin{array}{l}0.115 \\
\text { NS }\end{array}$ \\
\hline
\end{tabular}

The table shows that there was a statistically non-significant difference between group I and group II before hydration, $72 \mathrm{hr}$ and one week after hydration ( $p>0.05)$, but the decrease was statistically significant immediately after hydration $(\mathrm{p}<0.05)$. 


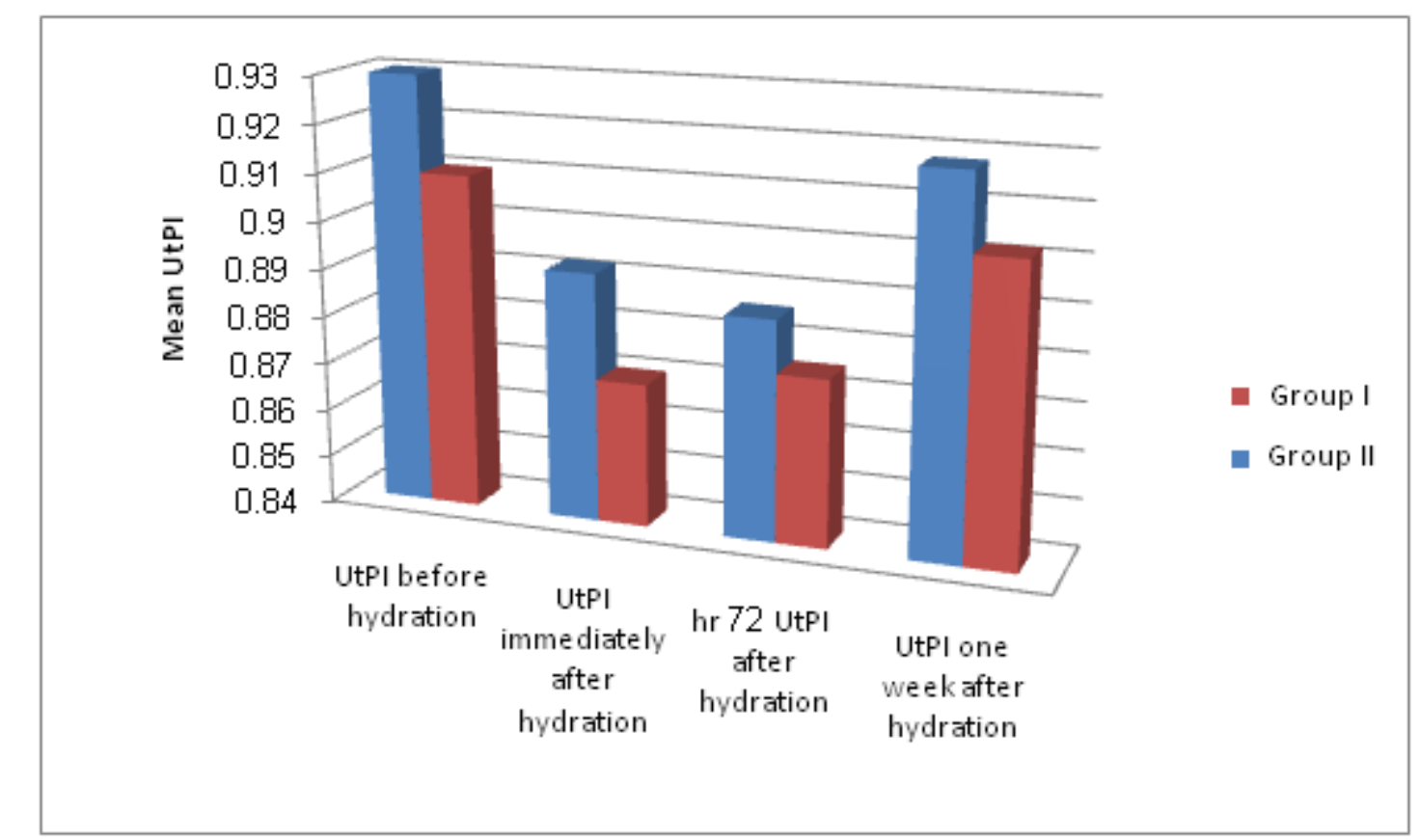

Diagram 5: comparison between group I and group II regarding uterine artery pulsatility index (UtPI)

\section{Discussion}

Oligohydramnios with intact membranes affects between $3 \%$ and $5 \%$ of pregnancies in the third trimester, but only $0.2 \%$ in the second trimester. Severe oligohydramnios is encountered less often than milder degrees. Oligohydramnios may be due to fetal urinary tract obstruction or absence of renal function, rupture of the membranes or intrauterine growth retardation (IUGR) ${ }^{(16)}$.Also, it can be due to post-term pregnancy, placental causes, maternal causes and drug induced. Idiopathic causes are also possible and called isolated or unexplained Oligohydramnios ${ }^{(\mathbf{1}, 17)}$.The aim of this study was to evaluate the effect of acute intravenous (hypotonic and isotonic) maternal hydration in pregnancies with third-trimester (32-37 weeks unexplained oligohydramnios $(\mathrm{AFI}<5 \mathrm{~cm})$, on amniotic fluid index and to evaluate umbilical and uterine artery Doppler changes.The present study included 60 pregnant women with third-trimester unexplained oligohydramnios six women dropped out and did not complete the study. Forty five women continued the study, without any maternal adverse effects and were randomized to two equal groups each of 22 and each group was allocated to the type of fluid infused. In this study there was no statistically significant differences between both groups as regard maternal age, weight, gestational age, gravidity and parity $(\mathrm{p}>0.05)$ i.e.both groups matched.The current study showed that the mean amniotic fluid index was $(3.86 \pm 0.99)$ in group I and $(3.73 \pm 1.03)$ in group II before hydration, i.e.that there was no statistically significant difference between both groups ( $p>0.05$ ).In group I, we infused 2 L normal saline i.v. (1 L/1 hr) for 2 hours, and we found that the mean amniotic fluid index increased from (3.86 \pm 0.99$)$ before hydration to $(4.73 \pm 1.28)$ immediately after hydration, was (4.41 \pm 1.3$) 72 \mathrm{hr}$ after hydration and $(4.41 \pm 1.3)$ one week after hydration. The range of amniotic fluid increased in group I after hydration, but was still in the range of oligohydramnios $(\mathrm{AFI} \leq 5)$ and did not reach the normal range (AFI $>5)$. Magann et $\boldsymbol{a l} .{ }^{(\mathbf{1 8})}$ conducted a study to estimate the effect of maternal intravenous hydration $(1000 \mathrm{ml}$ of normal saline over 30 minutes) on amniotic fluid volume. They showed that maternal saline intravenous hydration appeared to increase both the actual and sonographically estimated amniotic fluid volumes in normal third-trimester pregnancies. Shivkumar et al. (19) found that IV infusion of normal saline resulted in short term increase in AFI reaching the normal range (AFI $>5$ ). This because in our study, only normal saline was infused once in unexplained oligohydramnios but in study of Shivkumar et $\boldsymbol{a l}^{\left({ }^{(\mathbf{1 9})}\right.}$ normal saline, $5 \%$ dextrose and aminoacids infused on alternate days for three days per week in 
oligohydramnios with IUGR.In group II (i.v.hypotonic solution, $4.5 \%$ saline), the mean amniotic fluid index increased from (3.73 \pm 1.03$)$ before hydration to $(6.73 \pm 1.24)$ immediately after hydration, was $(5.86 \pm 0.83)$ $72 \mathrm{hr}$ and was $(5.41 \pm 0.73)$ one week after hydration. The mean of amniotic fluid index increased in group II after hydration and reached the normal range (AFI $>5)$ and was maintained for one week after i.v. hydration. Hofmeyr et al $^{(\mathbf{( 4 )}}$ concluded that intravenous hypotonic saline solution (1/2 normal saline), at a rate of $1000 \mathrm{ml}$ per hour for two hours, appeared to increase the amniotic fluid volume and that it may be beneficial in the management of oligohydramnios and in the prevention of oligohydramnios during labor or prior to external cephalic version. The increase in amniotic fluid volume reported by Shahnazi et $\boldsymbol{a l} .{ }^{(20)}$ which was different from our result could be related to that their patients were full term pregnancy and that the rate of infusion was one liter over 30 minutes (bolus method), but in our study most cases were preterm and the rate of infusion was slower (500 $\mathrm{ml} / 30$ minutes). Patrelli et $\boldsymbol{a l} .{ }^{(\mathbf{1})}$ studied the effect of intravenous infusion of isotonic solution in third trimester isolated oligohydramnios and found that there was a statistically significant increase in the mean AFI which increased from $(3.96 \pm 1.1)$ to $(7.77$ $\pm 1.5)$ after 7 days of therapy. The difference between this result and our results may be due to that in that study, isotonic solution was intravenously infused for 6 days with a rate of $1500 \mathrm{~mL}$ administered over 6 hours per day. Amniotic fluid index measurement was performed at 0 and 7 days, but in our study the infusion was done only once. Hofmeyr $\boldsymbol{e t}$ al. (4) reported a significant increase in mean amniotic fluid volume with intravenous hypotonic hydration ( $2 \mathrm{~L}$ over 2 hours), in unexplained oligohydramnios but with Isotonic intravenous hydration there was no measurable effect. Khalil et $\boldsymbol{a l l}^{(\mathbf{( 2 1 )}}$ evaluated the effect of different types of acute maternal hydration (IV hypotonic solution and IV isotonic solution) on amniotic fluid index in late third trimester (37-40weeks) with normal amniotic fluid and oligohydramnios. $\mathrm{He}$ reported that maternal hydration (intravenous hypotonic hydration) led to a significant increase in mean AFI in both oligohydramnios and in normal groups. Magann et al. ${ }^{(18)}$ concluded that intravenous hypotonic hydration in women with or without oligohydramnios was associated with an increase in amniotic fluid volume but intravenous isotonic hydration in women with oligohydramnios had no measurable impact on amniotic fluid volume. Khalil et al. ${ }^{(21)}$ reported that maternal hydration (intravenous hypotonic hydration) led to a significant reduction in the values of urine specific gravity in oligohydramnios and normal pregnancy. The authors concluded that maternal osmolality, as evidenced from urine specific gravity changes, with increased net flow of fluid from the mother to the fetus was the possible mechanism by which AFI might have been increased in both oligohydramnios and control groups. Oosterhof et al. ${ }^{(22)}$ found that acute maternal hydration with hypotonic fluid decreased urine specific gravity and plasma osmolality, which was reflected by hematocrit value, leading to an increase of urine production rate in the human fetus. They also showed that the near term human fetus could manage such acute changes in fluid osmolality by increasing the urine production rate to maintain its fluid homeostasis. This mechanism indicates that changes in maternal plasma osmolality and volume may play a crucial role in determining amniotic fluid volume. In our study, we have chosen to study the pulsatility index of fetal umbilical artery and uterine artery by using color Doppler ultrasound before and after hydration to detect any Doppler changes that could have any impact on amniotic fluid volume. The current study demonstrated that the mean umbilical artery pulsatility index (UmPI) value was $(0.836 \pm 0.063)$ in group I and $(0.874 \pm 0.074)$ in group II before hydration with statistically significant difference. In both groups, the mean UmPI value significantly decreased immediately after hydration, and significantly increased $72 \mathrm{hr}$ and one week after hydration. The current study showed that the mean uterine artery pulsatility index (UtPI) value was $(0.91 \pm 0.03)$ in group $I$ and $(0.93 \pm 0.05)$ in group II before hydration with no statistically significant difference. In group I, the mean UtPI value decreased significantly from $(0.91 \pm 0.03)$ before hydration to $(0.87 \pm 0.021)$ immediately after hydration, and increased significantly to $(0.875 \pm 0.019) 72 \mathrm{hr}$ after hydration, and increased significantly to $(0.902 \pm 0.02)$ one week after hydration .In group II, the mean UtPI value decreased 
significantly from $(0.93 \pm 0.05)$ before hydration to $(0.892 \pm 0.039)$ immediately after hydration, and significantly to $(0.886 \pm 0.036)$ $72 \mathrm{hr}$ after hydration, and significantly increased to $(0.918 \pm 0.041)$ one week after hydration.We were unable to demonstrate any statistically significant difference in fetal umbilical artery and uterine artery pulsatility index by using color Doppler ultrasound before and after hydration between both groups, except immediately after hydration. Comparison of Doppler values, among the studied patients, demonstrated that all pulsatility index measurements fell within the limits of the reference range before and after hydration and did not show any signs denoting pathological lesions either systemic or local. Ghafarnejad et $\boldsymbol{a l}{ }^{(\mathbf{1 3 )}}$ demonstrated improvement in uteroplacental perfusion detected by Doppler studies after maternal hydration and speculated that the improvement in uteroplacental perfusion could be one of the factors that affect amniotic fluid changes after maternal hydration.This study demonstrated that there was improvement in uteroplacental perfusion after maternal hydration which could be one of the factors that affect amniotic fluid changes after maternal hydration. The results of our study suggested that oligohydramnios responded to hypotonic fluid hydration and therefore may not warrant aggressive intervention unless potential fetal jeopardy is confirmed by other objective findings.

\section{Conclusion and recommendations}

Maternal intravenous hydration with hypotonic fluid can be used in the treatment of oligohydramnios being simple, noninvasive, cheap and acceptable method.

Further investigations are needed to determine if one day maternal hydration is sufficient to achieve a long term therapeutic tool for oligohydramnios, or an extended period of maternal intravenous hypotonic fluid hydration, for one week or until the time of delivery, and the length of time that the amniotic fluid volume remains increased.

Also if an extended period of maternal intravenous hypotonic fluid hydration is needed for treatment of oligohydramnios, studies are needed to determine the amount of fluid given each time and the time interval between them.

A long-term follow up of these cases of oligohydramnios treated with maternal hydration must be done to evaluate the fetal outcome and the mode of delivery.

\section{References \\ 1.Patrelli TS, Gizzo S, Cosmi E, Carpano MG, Gangi SD, Pedrazzi G, Piantelli G and Modena A B (2012 ) : Maternal hydration therapy improves the quantity of amniotic fluid and the Ppegnancy outcome in third-trimester isolated oligohydramnios . A controlled randomized institutional trial. $\mathbf{J}$ .Ultrasound. Med ., 31:239-44.}

2. Nabhan AF and Abdelmoula YA (2009): Amniotic fluid index versus single deepest vertical pocket: a meta-analysis of randomized controlled trials. Int. J. GynecolObstet., 104:184-188.

3. Johnson JM, Chauhan SP, Ennen CS, Niederhauser A and Magann EF (2007) : A comparison of 3 criteria of oligohydramnios in identifying peripartum complications: a secondary analysis. Am. J. ObstetGynecol. , 197: 207: 207.215.

4. Hofmeyr GJ, Gulmezoglu AM and Novikova $N$ (2002): Maternal hydration for increasing amniotic fluid volume in oligohydramnios and normal amniotic fluid volume (Review). Cochrane Database Syst. Rev., 1:134-142.

5. Jain L and Eaton DC (2006) : Physiology of fetal lung fluid clearance and the effect of labor. Semin. Perinatol.,30: 34-43.

6. Lam H, Leung WC, Lee CP and Lao TT (2006) : Amniotic fluid volume at 41 weeks and infant outcome. J. Repord. Med., 51: 484-88.

7. Modena AB and Fieni S (2004): Amniotic fluid dynamics. Acta Biomed., 75: 11-14.

8. Beall MH, Van den Wijngaard JPHM, Van Gemert MJC and Ross MG (2007): Regulation of amniotic fluid volume. Placenta, 28: 824-832.

9. Borges VTM, Rososchansky J, Abbade JF, Dias A, Peraçoli JC and Rudge MVC (2011): Effect of maternal hydration on the increase of amniotic fluid index. Brazilian J. of Medical and Biological Research, 44: 263-66.

10. James DK (2008) : Oligohydramnios. In: 
High Risk Pregnancy Management Options. $3^{\text {rd }}$ ed.James DK, Steer PJ, Weiner CP, Gonik B, Saunders Elsevier, pp:258-278.

11. Umber A (2010): Intravenous versus oral maternal hydration therapy for increasing amniotic fluid volume. Annals., 16: 14-16.

12.Romero-Gutiérrez G, Herrera-Coria J and Ruiz-Treviño AS( 2014 ) : Association of Doppler flowmetry with perinatal outcome in patients with oligohydramnios. Rev. Med. Inst. Mex. Seguro.Soc., 52: 510-515.

13. Ghafarnejad M, Tehrani M B, Anaraki F B, Mood N I and Nasehi L (2009): Oral hydration therapy in oligohydramnios. J. Obstet. Gynaecol. Res ., 35: 895-900.

14. Freeman RK, Moore PJ, Lagrew DCand Dowing MR (2001): Prolonged pregnancy and changes in color Doppler indices of umbilical artery. Br. Med .J., 2: 1450-1451.

15. Frusca T, Soregaroli M, Valcamonico A, Guandalini F and Danti L (1997): Doppler velocimetry of the uterine arteries in nulliparous women. Early Hum. Dev., 48:177-185.

16. Xu H, Hofmeyr J, Roy C and Fraser W (2007): Intrapartum amnioinfusion for meconium-stained amniotic fluid: a systematic review of randomized control trials. BJOG., 114: 383-390.

17. Sherer DM, Langer $O$ and Oligohydramnios (2001): Use and misuse in clinical management Division of Maternal-Fetal Medicine.
Ultrasound Obstet. Gynecol., 18: 411119.

18. Magann EF, Sanderson M, Martin JN JR and Chauhan SP (2000) : The amniotic fluid index, single deepest pocket, and two diameter pocket in normal human pregnancy. Am. J. Obstet.Gynecol., 182: 1581-88.

19. Shivkumar PV, Tayade SA, Pramodkumar, Tayade AT, Bagde ND and Bagde MN (2011) : The role of intravenous hydration and amino infusion in intrauterine growth restriction and oligohydramnios. Int. J. Biol. Med. Res. , 2: 1078-1083.

20. Shahnazi M, Meli MS, Hamoony F, Sadrimehr F, Samani FG and Koshavar H (2012) : The effects of intravenous hydration on amniotic fluid volume and pregnancy outcomes in women with term pregnancy and oligohydramnios: a randomized clinical trial. Journal of Caring Sciences, 1: 123-28.

21. Khalil A, Noussair $M$ and Abd-Elkarim M (2009) : Comparative study of maternal hydration in increasing amniotic fluid volume in unexplained oligohydramnios. Master of Obstetric and Gynecology Thesis, Faculty of Medicine. Benha University.

22. Oosterhof H, Haak MC and Aarnoudse JG (2000): Acute maternal rehydration increases the urine production rate in the near-term human fetus. Am. J. Obstet. Gynecol., 183: 226-229. 